\section{Striking the right balance}

\section{Osborne Clarke is one of Europe's most respected law firms, and advises market-leading and high-performing organizations on their $U K$ and international legal needs. Any enquiries regarding this column should be sent by email to Stephen Groom (stephen. groom@osborneclarke .com)}

\section{Complaint by Which?}

exercise their right to disallow websites from tracking their choices. As both referee and mediator, I have to strike the right balance between the two. A mutually agreeable outcome, while challenging, must still be possible. And nobody needs to get their fingers burnt.

\section{Top tips on the road to compliance}

- Identify which cookies are operating on your website.

- Confirm the purpose of each of the cookies - in particular whether you link it to other information about users such as usernames.

- Identify what data each cookie holds.

- Confirm the type of cookie it is (ie session or persistent).

- If it is a persistent cookie, determine its lifespan.

- Identify third-party cookies.

- Confirm whether your privacy policy currently provides accurate and clear information about each cookie.

\section{Debit/credit travel payment surcharge crackdown looms}

\author{
Nick Johnson \\ Journal of Direct, Data and Digital Marketing Practice (2011) 13, 168-170. \\ doi:10.1057/dddmp.2011.34
}

(The following items of current interest come from the Marketing Law website of Osborne Clarke (http://www.marketinglaw.co.uk), where they first appeared in July 2011).

Topic: Financial services

Who: Office of Fair Trading

Where: United Kingdom

When: 28 June 2011

Law stated as at: 11 July 2011

\section{What happened}

The Office of Fair Trading (OFT) has told passenger travel companies to get much clearer on debit and credit card surcharges, or face enforcement action under the Consumer Protection from Unfair Trading Regulations 2008 (CPRs).

In its response to a super complaint from Which? under the Enterprise Act 2002, the OFT concludes that many airlines and other operators in 
this sector often present these surcharges too late in the buying process - after the customer has already spent considerable time making their booking and supplying personal information. It has called on operators to change their practices voluntarily so as to make charges clear to consumers upfront, or face legal proceedings under the CPRs.

In particular, it makes the following recommendations to online retailers:

\section{Surcharges}

\section{Transparency}

\section{Payment by debit card 'the norm'}

\section{There are other payment methods in the pipeline}

- Price references within the trader's website: 'whenever prices are displayed on a website, surcharges must be made clearly available via just "one click" and not simply be revealed at a late stage in the shopping process'.

- Disclosures in advertising: 'retailers should clearly reference card surcharges on any advertising material when prices are being promoted'.

As well as challenging the sector to move to greater price transparency in place of what it sees as 'drip pricing', the OFT has also asked the UK government to legislate to ban surcharging for debit (as opposed to credit) cards.

\section{Why this matters}

The OFT estimates that UK consumers spent more than $£ 300 \mathrm{~m}$ on payment surcharges in 2010 with just 10 major airlines. The OFT is not saying that surcharges must stop entirely, or must be limited to no more than the actual cost of processing the payment: it says:

Traders should still be able to impose surcharges for [payment mechanisms other than debit cards] such as credit cards, which can be more costly to process, provided that they meet ... minimum transparency requirements.

However, the OFT is plainly trying to reach a position where the headline price advertised is inclusive of all charges for paying by debit card, which the OFT sees as 'the online equivalent to cash'. And it is plainly not going to stop at just the travel sector, saying:

... our views on surcharging apply across all commercial traders in the UK ... If necessary we will consider enforcement action in other sectors in due course ...

Of course, as emerging e-money currencies start to be used more widely by consumers, the OFT's assessment of debit card as being the 'almost universal payment method for today's online consumers' may quickly become outdated. However, where these e-money payment methods are less costly to process, it is likely that we will now see traders making much more effort to encourage uptake and usage by consumers, so as to increase profit-per-sale against a headline price that is inclusive of debit card processing charges.

Separately, as reported elsewhere in this month's http://www .marketinglaw.co.uk updates, it now looks like traders and payments 
sector operators will also have to factor in developments under the Consumer Rights Directive. Article 19 of the Directive states:

Member States shall prohibit traders from charging consumers, in respect of the use of a given means of payment, fees that exceed the cost borne by the trader for the use of such means.

Assuming the Directive is approved by the Council of Ministers when they vote on it this month (July 2011), this means that payment card surcharges will be limited to no more than passing on the actual cost to the trader: no element of mark-up will be permitted. It is currently proposed that the Directive would require transposition into local member states' laws by the end of 2013.

In the meantime, expect yet more small print disclosure in advertisements, along the lines 'Credit card surcharge applies', and widespread adoption of 'Payment method charges' sections within traders' websites.

Nick Johnson, Partner, Osborne Clarke, London

E-mail: nick.johnson@osborneclarke.com

\section{Subjective redundancy selection criteria can be OK for 'creative' roles}

\section{Christopher Stack and Jenny Wotherspoon}

Journal of Direct, Data and Digital Marketing Practice (2011) 13, 170-173. doi:10.1057/dddmp.2011.35

Topic: Discrimination

Who: Mr P Lancaster v TBWA Manchester

Where: Employment Tribunal

When: Judgment handed down on 14 June 2011

\section{What happened}

\section{Background}

Mr Lancaster was employed by TBWA Manchester, a marketing and advertising agency, as a Senior Art Director from 24 February 2003 until 13 May 2009 when he was dismissed for redundancy at the age of 50. He suffered from a panic and social anxiety disorder, which amounted to a disability for the purposes of the Disability Discrimination Act 1995 (DDA 1995).

Like most businesses, TBWA Manchester was affected by the global economic crisis and, in particular, the account on which Mr Lancaster 